\title{
Thoracic Intradural Extramedullary AV Malformation Presenting as Foix- Alajouanine Syndrome: A Case Report
}

\author{
${ }^{1}$ S Patwari, A Verma, ${ }^{1}$ A Srivastava, ${ }^{1} \mathbf{R}$ C Shukla \\ ${ }^{1}$ Department of Radio diagnosis \& Imaging, Institute of Medical Sciences, Banaras Hindu \\ University, Varanasi, India
}

\begin{abstract}
Acute or subacute myelopathy with spontaneous thrombosis of the veins in a patient with a spinal arteriovenous malformation (AVM) has been referred to as "Foix-Alajouanine syndrome (FAS)". A previously healthy 35-year-old man developed neurological illness with progressive lower extremity weakness and low back pain. MRI demonstrated diffuse swelling of the thoracic spinal cord, suggesting myelopathy with few intradural extramedullary serpeginous flow voids. We report a case of Foix-Alajouanine syndrome with a review of the literature.
\end{abstract}

Keywords: Arteriovenous malformation, Foix-Alajouanine syndrome, Myelopathy

\section{Introduction}

In 1926, Foix and Alajouanine described a subacute myelopathy produced by a thrombotic process of the spinal cord that ultimately caused death. ${ }^{1}$ At autopsy they discovered necrosis of the spinal cord and numerous thickened tortuous vessels lying on the surface of the cord. Years later, in 1931, Lheritte et al, recognized this process to be associate with spinal arteriovenous malformation (AVM) .It was generally believed that therapidly progressive myelopathy resulted from thrombosis of this abnormal vessel within the spinal cord. Consequently, this process, which came to be known as the Foix-Alajouanine syndrome (FAS), was felt to be irreversible and carry a poor prognosis. ${ }^{2}$ In most patients with this condition, sensory symptoms, pain and leg weakness are the most common initial symptoms. ${ }^{3-5}$

Correspondence to: Dr. Ashish Verma Department of Radio diagnosis \& Imaging Institute of Medical Sciences, Banaras Hindu University, Varanasi - 221005

Email: drdnv5@gmail.com

\section{Case Report}

A 35-year-old male presented with progressive lower extremity weakness and urinary retention. He also complained of lower back pain and paresthesias. There was no history of fever or trauma. Examination revealed reduced tone and power in bilateral lower limbs with some distal sensory loss in the stocking pattern. The plantar reflex in the patient was down going. Routine lab investigations were within normal limits. CSF examination showed increased protein $(163 \mathrm{mg} / \mathrm{dL}), 102 \mathrm{red}$ cells $/ \mathrm{mm}^{3}$, with normal white cells $\left(2 / \mathrm{mm}^{3}\right)$. A dorsolumbar MRI showed multiple serpeginous flow voids (Fig 1) some showing post contrast enhancement (Fig 2) noted along the anterior and posterior surface of the spinal cord in the dorsal region with associated diffuse long segment cord swelling and abnormal signal intensity (Fig 1). This spinal arteriovenous malformation was suspected to be causing ischemia of the spinal cord, resulting in lower extremity weakness. The patient declined any therapeutic surgical or neuroradiological intervention, and was eventually referred for physical rehabilitation. 


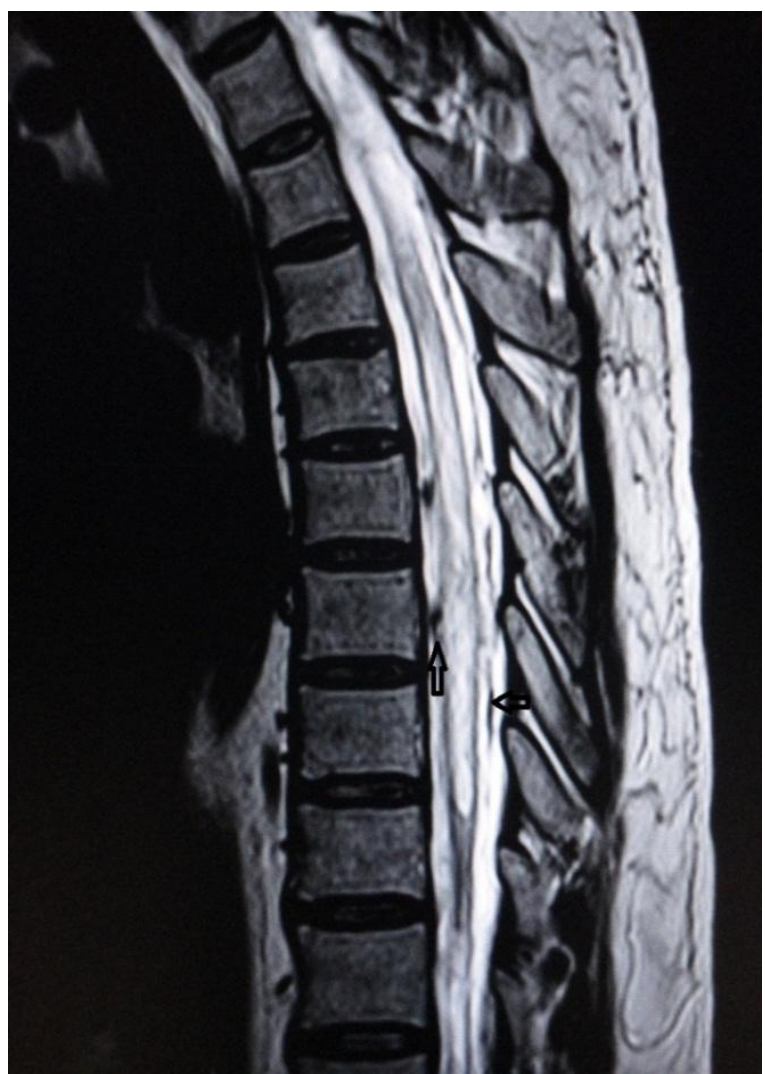

Fig 1: T2W Sagittal image shows diffuse swelling with change in signal intensity involving the spinal cord which suggests myelopathy. Also noted are multiple serpeginous intradural flow voids (arrows) suggestive of AVM.

\section{Discussion}

Foix-Alajouanine syndrome is a subacute disorder that gradually evolves over 1 to 5 years. The majority of affected patients are males older than 50 years of age. About half of the patients have an acute onset of pain and dysesthesia or may complain of intermittent sciatica. Patients may have a fullblown myelopathic picture or may have transient weakness and sensory disturbances followed by progressive radiculospinal symptoms. There may also be bowel or bladder incontinence and impotence.

Foix-Alajouanine syndrome predominantly affects the lower thoracic and/or lumbosacral levels; cervical cord involvement is rare. Findings include necrosis of the affected cord regions. Gray matter (as compared to white matter) structures are more severely involved. Such findings were noted in our case, we noted areas of acute edema but few areas also equaled fluid intensity, representing areas of

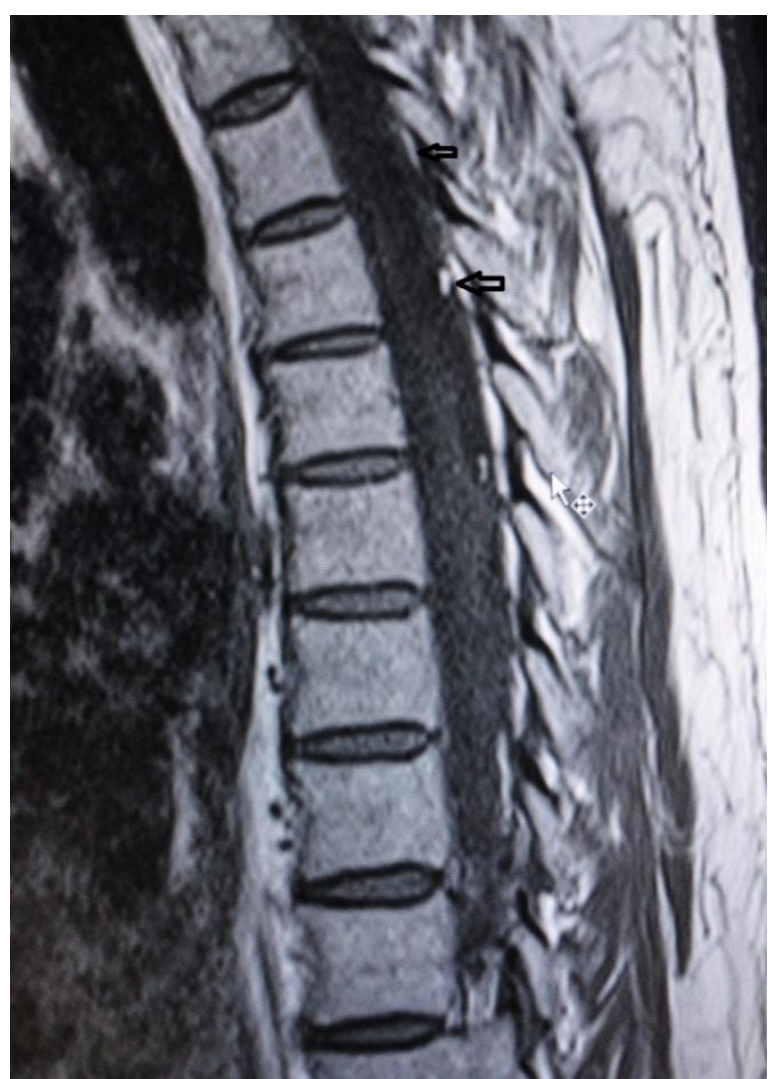

Fig 2: Post Gd T1W Sagittal image shows few enhancing intradural vessels.

necrosis and cystic degeneration. Masses of enlarged, tortuous, and thick-walled subarachnoid veins are observed overlying the surface of the cord (primarily on the posterior aspect). Smaller blood vessels with thickened fibrotic walls also are present within the affected spinal cord segments. The enlarged, abnormal veins are associated with dural arteriovenous (AV) shunt or fistulas, usually intradurally but rarely extradurally. These AV shunts are associated with reflux of arterial blood into the venous drainage of the cord. This results in increased venous pressure in the affected regions of the spinal cord, often leading to ischemic injury. ${ }^{6}$

The suspected diagnosis of spinal dural AVM may be confirmed by angiogram, however despite its high sensitivity, arteriography may be inconclusive. Van Dijk et $\mathrm{al}^{5}$ described 
two patients whose angiograms did not reveal a spinal AVM, although the patients had classic signs and symptoms, both clinically and on MRI. Criscuolo et $\mathrm{al}^{4}$ described two patients with diagnosis of Foix-Alajouanine syndrome and a negative spinal arteriography. When a patient presents a subacute clinical picture, correlated to venous congestion phase, the remission of the symptoms can be placed by intradurally surgical division of the shunting vein to the venous plexus. However, the potential for a reversal of this process of vascular lesion, including surgical stripping of the dorsal veins of the spinal cord has been advocated. At these cases, the surgery often led to clinical deterioration due to total lack of spinal cord normal venous drainage. Some authors describe similar postoperative results achieved by endovascular embolization by liquid adhesive embolics. Therefore, despite of some controversies, the interventional and surgical procedure are the standard treatment, preventing clinical deterioration and improvements is possible to some extent.

Foix-Alajouaine syndrome is a rare syndrome characterized by subacute progressive myelopathy caused by subacute congestive and ischemic effects due to an arteriovenous malformation. Arteriography is a sensitive diagnostics tools to vascular alterations, but can be inconclusive at some point. A correlation of meticulously gathered clinical findings to MRI picture seems to be the only confirmative method to diagnose the disease.

\section{References}

1. Foix C, Alajouanine T. La myélite nécrotique subaigue. Rev Neurol (Paris) 1926; 2:1-42.

2. Wirth FP Jr, Post KD, Di Chiro G, et al. Foix-Alajouanine disease. Spontaneous thrombosis of a spinal cord arteriovenous malformation: a case report. Neurology 1970; 20:1114-1118.

3. Tobin WD, Layton DD. The diagnosis and natural history of spinal cord arteriovenous malformations. Mayo Clin Proc 1976; 51:637-646.

4. Criscuolo GR, Oldfield EH, Doppman JL et al. Reversible acute and subacute myelopathy in patients with dural arteriovenous fistulas: Foix-Alajouanine syndrome reconsidered. J Neurosurg 1989; 70:354-359.

5. Van Dijk JMC, Ter B rugge KG, WillinskyRA, et al. Multidisciplinary management of spinal dural arterovenous fistulas: clinical presentation and long-term follow-up in 49 patients. Stroke 2002; 33:15781583.

6. Mishra R, Kaw R. Foix-Alajouanine syndrome: an uncommon cause of myelopathy from an anatomic variant circulation. South Med J. 2005; 98(5):567-9. 